\title{
Encounter Facebook: An Appraisal on the Making and Unmaking of Ethiopian University Students' Socio-politics
}

\author{
Shimellis Hailu Dessie ${ }^{1, *}$, Haleluja Adane ${ }^{2}$ \\ ${ }^{1}$ Department of Political Science and International Relations, Wollo University, Dessie, Ethiopia \\ ${ }^{2}$ Department of Journalism and Communication, Ambo University, Ambo, Ethiopia
}

Email address:

kumarraatura $a$ gmail.com (S. H. Dessie), shimellishailu $a$ yahoo.com (S. H. Dessie)

${ }^{*}$ Corresponding author

\section{To cite this article:}

Shimellis Hailu Dessie, Haleluja Adane. Encounter Facebook: An Appraisal on the Making and Unmaking of Ethiopian University Students' Socio-politics. Advances in Sciences and Humanities. Vol. 5, No. 6, 2019, pp. 148-159. doi: 10.11648/j.ash.20190506.13

Received: July 6, 2019; Accepted: July 26, 2019; Published: December 24, 2019

\begin{abstract}
The general objective of this research is to assess the effects of Face book on the making and unmaking of University students socio-political activities. To achieve the objective, both primary and secondary sources of data were collected and interpreted using mixed research approach. As far as primary sources of data were concerned, first hand information collected from 500 University students via questionnaires, interviews and focus group discussions. Furthermore, the primary data were substantiated by secondary sources. Using the data the researchers reached upon the following conclusions; the general assessment of facebook usage among Ethiopian public University students is in perspectives. The effects of facebook usage on Ethiopian university students' academic performances, is in perspective. Majority of the university students explain the positive contribution of facebook on students' academic performance while some others tudents are explain as facebook usage affects their academic performances negatively. In similar manner, facebook usage has both positive and negative effects on University students' social interactions. Facebook helps students to deliver message accurately at all time, contact with relatives and friends at distance with less cost and easily while it deteriorated social gathering and discussion, and promote individualism. However, in relation to facebook usage and political activism, the finding shows that majority of Ethiopian University students are passive in overtly participating in online political activism. Generally, it is possible to conclude that facebook has both positive and negative effects on Ethiopian university students' socio-politics, which seek attention to create awareness among university students in order to exploit the fruits of facebook absolutely and reduce its negative impacts.
\end{abstract}

Keywords: Facebook, Socio-politics, Social Capitals, Academic Performances

\section{Introduction}

The Worldwide Web originally created in 1990 for US military forces gradually developed to convenient tool that issued by civilians for communication, entertainment, and learning purposes. One of the most popular and recognized platforms used on the Internet are social networking sites such as Face book. Face book being at the forefront of the social media vogue, has over 1.71 billion monthly active users with $15 \%$ increase per year and 1.13 billion people log on it daily [1]. It is emerged on February 4, 2004 when a 19year-old sophomore Harvard student, Mark Zukerberg founded the revolutionary site to connect Harvard University students [2]. Nevertheless, later, this site allowed users to build social networks with hundreds or even thousands of people around the world of which university students are one of the primary demographics using Facebook, with features such as photos, wall posts, and status updates becoming seemingly appealing to those who want to connect with their friends [3].

Even though Facebook is now used by much wider variety of users, university students are still its "biggest fans". Demographically, $79.7 \%$ of all active Facebook users are between age 18-34. Results from a recent paper Ellison et al. (2007; as cited in Firomsa, 2014) reported that $94 \%$ of College students are active Facebook users, spending 60-90 minutes online each day communicating with their friends. 
Similarly, Wiley and Sisson (2006; as cited in Firomsa, 2014) conducted a large survey on college students from universities in the developing countries indicated that $91 \%$ of students use Facebook. Furthermore, the Zephoria report of 2016 shows that as there are 83 million fake Facebook accounts which may participate in indirect political activism in third world countries.

Ethiopia as one of developing countries has also under the influence of Facebook with around 3.7 million users in which half of them are higher education students [4]. Though this social network generates billions of dollars for the developer and assists to contact a relatives detached for long period within fraction of seconds, it has impacts on the users in general and on university students' socio-political and interpersonal relationship in particular. So, this research attempted to investigate the effects of Facebook usage on socio-political and interpersonal relationship among public university students in Ethiopia.

\section{Statement of the Problem}

Over the past several years, social networking websites have made their debut and appear currently, there are hundreds of social networking websites, the largest and most popular of which being Facebook. It was developed by Mark Zuckerberg in 2004 and currently boasts and has membership of nearly 1.71 billion users [5]. In Ethiopia, the Facebook users increase from time to time with the major users being students and staffs in higher education institutions. According to Internet World Stats (2016), there are more than 3.7 million Facebook users in Ethiopia. Besides, more than 50\% of Facebook users are found in the age interval of 16-24 and live in the urban area of the country. Usage of Facebook in Ethiopia has increased 500\% within five years since 2010 and total minutes spent on Facebook rose nearly 300\% in 2013 compared to a year before. Higher education institutions (HEI) students' Facebook users spent an average of 18 hours online every month [6].

Moreover, from the total Facebook users in Ethiopia, the usage by this age group (16-24) has been increased from $38 \%$ in 2010 to $51.6 \%$ in 2014 [7]. The percentage of this age group is relatively greater than the corresponding percentages in most African countries such as Kenya, Tanzania, Senegal and Cameroon $(48.3 \%, 45.6 \%, 38 \%$ and $50.3 \%$ respectively). In Ethiopia, most of the HEI students are found in these active Facebook users age groups. Thus, the introduction of technological innovations into countries has always been the adversaries and blessing opportunities for socio-economic and political life of human beings. Every technological innovation has been a topic of debate and centre of researchers' attention and the same is the case with the development of Facebook. The increment of Facebook users, huge engagement of young university students and its effects on socio-political and interpersonal relations of the young generations seek the attention of many researchers.
However, in Ethiopia, limited researches have been conducted to pinpoint the effect of Facebook and findings identified both bright and dark aspects. For Example, Nebiat Negussie and Girum Ketema (2014) conducted research entitled, "Relationship between Facebook Practice and Academic Performance of University Students" and come up with the finding that there is no significant relationship between usage time and frequency of login Facebook with students GPA. Nevertheless, the researchers find out, as there is moderate negative relationship between using mobile phone to visit Facebook and students academic performance [8]. Firomsa Bedasa (2014) also conducted a research on facebook with the title of 'The Impacts of Facebook Usage on Students' Academic Performance' and find out that long time spent on Facebook and addiction to it negatively and significantly affects the academic performance of Wollega University main campus regular students. Furthermore, Kassahun G/Medhin (2014) conducted a research on the nexus between the use of Facebook and psychosocial adjustment among selected preparatory school in Addis Ababa and found out that higher Facebook usage resulted in lower psychosocial adjustment.

Both of the first two studies have the same limitation. Both limited in scope and geographical coverage. Nebiat and Girum study was limited in both its scope and geographical coverage by focusing only on dealing with the practice of Facebook and academic performance among Jimma University post graduate students while Firomsa's study limited to the study of the impacts of the use of facebook on academic performance of Wollega University main campus regular students. Whereas Kassahun's study limited, geographically to Addis Ababa preparatory schools and in content focus only on Facebook-psychosocial adjustment nexus.

The other Facebook related study conducted in Ethiopia was study performed by the collaboration of professionals from University of Oxford, Programme in Comparative Media Law and Society and Addis Ababa University with relatively nationwide scope but specific issue: Hate speech on social media and election in Ethiopia. This study pinpoint to the hate and dangerous speech during election in Ethiopia specifically depending upon election related statement during the 2015 Ethiopian general election [9]. Therefore, this sort of report has a shortcoming to cover the wide issues rotating on the social media specifically on Facebook. Although, most of the researches performed in Ethiopia concerning Facebook took University or college students as target groups, they did not cover nationwide to bring the comprehensive picture of the effects of Facebook on university students. Also most of the researches conducted were focus on effects of facebook usage on students' academic performance let alone social, political and interpersonal relationship. Therefore, in this study an attempt would be done to gain an understanding of the current effects of the use of Facebook on socio-political and interpersonal relations among public university students in Ethiopia. 


\section{Research Methodology}

For this study, a mixed research approach employed to gather both primary and secondary data sources. The mixed approach contains different strategic model; from these the researchers select sequential explanatory strategy. This is because sequential explanatory strategy helps researchers to confirm, cross-validate or corporate a finding of data collected using two different methods in a single study by exploiting the strong side of both approaches. Therefore, it is the straightforward strategy to explore the effects of the increment of the use of Facebook on Ethiopian university students' socio-political and interpersonal relations. The quantitative data gathered through Questionnaires were cross-validated against qualitative data collected using indepth interviews and Focus Group Discussions. First quantitative data collected and analyzed, and the quantitative data were substantiated and verified using qualitative data.

\subsection{Population, Sample and Sampling Techniques}

The population for this study was all-regular public university students reside in Amhara National Regional State who have facebook accounts whereas the target population is the regular students of the four selected universities and have facebook accounts. There are seven public universities in Amhara National Regional State divided into four generations. To identify sample random, convenient and purposive sampling techniques would be used. To have fullfledged information on the effects of Facebook on university students, the researchers selected four universities proportionally from all the four-generation using simple random sampling. By using lottery method, University of Gonder, Wollo University, Mekdela Amba University and Woldia University were taken as sample.

From identified universities, individual students were selected using both random and convenience sampling techniques, which is a method by which a researcher like purposive sampling intentionally draws samples considering certain factors that are deemed relevant for the research [10]. Therefore, the researchers employed both random and convenience sampling technique to include any students using Facebook and available at the time of data collection. The sample size determined for this study is justified by the fact that if we take each of the university students concerning the use of Facebook, they are at relative age and almost have relative awareness, implying the possibility of taking medium sample size.

For this study, therefore, the researchers decided to draw medium sample size. As far as sample size determination is concerned, from different methods, the researchers used the method developed by Carvalho, (1994) as cited in [11]. Accordingly, the method recommends for target population between 35,000 to 150,000 : sample size low 200, medium 500 and high 800 depending upon the characteristics of target population. Since there is no huge variation among university students concerning Facebook usage, the researchers adopted medium sample size, 500 as representative.

\subsection{Source of Data and Methods of Data Collection}

In order to accomplish the purposes of this research, both secondary and primary sources of information were collected. As far as secondary sources were concerned, journal articles, newspapers, reports, discourse analysis and official documents were taken as sources. To this end, reviewing relevant literature to compile in a form of over view of what is currently known about the use of Facebook at worldwide in general and in Ethiopian in particular would be carried out. Also, discourse analysis would be made to draw together the level of political and social discourse rotating on the Facebook in order to understand the effects of Facebook on students' socio-political activities. Using secondary sources as base, primary sources would be collected from target population via interviews, questionnaires and focus group discussion.

\subsection{Data Presentation, Analysis and Interpretation}

The quantitative data is analyzed using descriptive analysis-Statistical Package for Social Science (SPSS version 20). While qualitative data is analyzed by arranging and portraying the data collected through interviews and FGD in a way that help to detect patterns or problems, explore associations that exist in the data. In this analysis, reiteration and elaborations of key concepts and suggestions was made on the findings that fit with the existing literature under investigation. In doing so, the researchers were identified dissimilarities while comparing the findings secured against literature reviews. In addition, discourse analysis was conducted on some university students' socio-political dialogues on Facebook. Finally, the quantitative and qualitative data integrated together sequentially; quantitative data followed and verified by qualitative data.

\section{Conceptual and Literature Reviews}

\subsection{Media: Concepts and Typology}

According to Bainbridge et al(2011), media defined as content and distribution mechanisms through which information and/or entertainment are transmitted. Furthermore, Allen \& Unwin (2004) stated that, "Media is the plural form of 'medium'. Broadly understood, a medium is an intermediate agency that enables communication to take place. The media are a specific institution in society, informed by particular interests, practices, norms and values. Stringently speaking, the word 'media' refers to anything through which something else can be transmitted what are often referred to as the media or mass media, message transmitters designed to attract the greatest number of audience members, such as newspapers, television, film, radio and the Internet [12]. It means that the types of media we will be looking at are all involved in communication; the distinct between communication and media is that 'communication is the process of sending and receiving messages whereas media are the means of communication 
and transmission'. Media are therefore the mechanisms through which we communicate with other people (Ibid).

When we talk about media, it is mandatory to explain mass media too since they service as the bridge between different sections of society. For instance, mass media link buyers with sellers bring voters and political campaigners together and connect one society with the other. So what is mass media or mass communication? Mass communication is the process of preparing public content of message (identical copy of message) and sending to diversified society/peoples. These heterogeneous audiences are scattered in their nature and they are geographically dispatched. For example, The Voice of America (VOA) is broadcast from Washington DC; however, people from different continent, countries, and cities and rural areas listen to it as the same time even though they are physically far from each other.

\subsection{Types of Media}

There are different types of media. These are electronic media (television and radio), print media like newspaper, magazine, pamphlet, newsletter, brochure, and online media. These mass media have very different textual characteristics and varying kinds of political influence. "Television has become the most powerful mass medium in the industrialized world' because it brings motion picture and coming up with the reality [13]. For its visual image, television is now a standard feature not only in households but also in public spaces, such as airports, hotels and even public transport like bus, train and taxi (Ibid). For instance, in Australia television penetration has reached $99 \%$ of households and many have more than one TV and over its citizens spent more than 20 hours a week (Productivity Commission, 2000, cited in [13]).

The other broadcast medium is radio; it is the most understandable mass medium in the world that needs only ear since it is a blind medium (only voice). Like television, radio can also quickly bring latest/update information to its listeners as a breaking news stories. Since it relies on audio, radio arguably more than other mass media, has a ubiquitous presence in the day to day activities. Radio is one of the mass media that enables listeners to inform, educate and entertain them. Tuggle et al (2007) emphasize the uniqueness of radio in informing the latest event in a short period. "Radio is the fastest and most widely dispersed mass medium. It is ubiquitous. It's everywhere". [14]. Because when big newsbreaks, radio inform the public at first hand and radio can provide dozen of news items within four minutes (Ibid). Tuggle describes the more advantageous of radio than other media. It is the cheapest, portable and only needs the ear. Radio can be available everywhere, in the car, mobile cell phone, in home. Even people listen to radio in stadium while they are watching football game (Ibid).

Now days, because of technology, newspapers, television and radio outlets have online versions of their publications and programs. Anyone can access webcasts of events, listen to web radio and watch television newscasts and program on the Internet. Allen \& Unwin (2004) further stated that online media gave greater potential for interactivity, a feature that could change fundamentally the relations between media producers, public figures and the public.

\subsection{Internet News Media}

Internet is one of the modern mass media that has both print and electronic media feature. The Internet provides text message, audio and video contents, and shows still images. It continues to initiate a Cultural Revolution in many ways, including faster and more comprehensive forms of personal correspondence, explosion in the amount of information and types of information available. It also brings new forms of shopping, financial trading and the supply of services. Internet news media cannot only provide information faster, but they also are better equipped to provide more comprehensive background information. Newspapers have always offered better context in news stories than broadcast media, but the Internet news media can tap into databases that supply much more extensive contextual information" (Ibid).

\subsection{Social Media}

Social media is the latest version of mass media and widely used in almost in all counties. These social media/social networking sites are mostly used by youth. According to [15], "Social media refers to the means of interactions among people in which they create share, exchange and comment contents among themselves in virtual communities and networks. This implies that people create their own accounts and share information that they believe good to know their friends or colleagues. In addition, they comment on someone's or friends' post what they feel about the picture or the text. Furthermore, they may reflect their feelings by liking the post. Some of social media are internet, social networking, web2.0, Facebook, YouTube, blog [16], Twitter, Wikis, media (audio, photo, video, text), sharing tools, networking platform [17]. All these names are relatively new words in political vocabulary, new concepts and new opportunities in transferring and receiving ideas, feelings and messages via the Internet (Ibid).

Among the variety of social media, Facebook is the most widely known and used social networking site. As Mingle et al (2016) elaborated, Facebook users share ideas and pictures with friends and family members. Students also use Facebook to keep in touch with their former classmates (high school) and workmates. It enables them to create new relationships and friendship with people. Amofa-Serwa and Dadzie (2015) cited in [18]) argued that Facebook was the most preferred social media site among students who used social media." More than other social media, Facebook has been importantly and frequently used in the past decade [19]. According to Caerset al, at the end of 2012, more than one billion people monthly active users of Facebook. In addition, $80 \%$ of those users reside outside the US, and its services available in 70 different languages [20]. Currently the number of language used on facebook is expected to increase. In his latest post the Facebook founder and CEO, 
Mark Zuckerber, explained that there are more than 2.5 billion people using Facebook at least once a month as Zuckerber, 2018 posted and accessed on July 25.

As research indicates, Facebook is mostly used by young aged 18 to 29. These are university students and graduates who are recently employed. According to research conducted by Perrin, age is strong correlated with social media usage. "Those ages 18 to 29 have always been the most likely users of social media. Today, $90 \%$ of young adults use social media." [20]. These young use smartphone to get the social media services; for instance, the study conducted by Noonan and Piatt (2014) and focused on global social media directory indicates, $43 \%$ of Sub-Saharan Africa smartphone are used by young people. " $43 \%$ of SSA smartphone or tablet users are aged 16-24 as compared to $26 \%$ of worldwide smartphone users worldwide." [21]. Furthermore, research conducted in Oman also indicates that $80 \%$ of students use their mobile phone to access social media network. It indicates that smartphone helped increasing students' access to peers and flexibility of staying in touch with their friends (Ibid). Meanwhile, 58\% of SSA Internet users think that social media is the most important online activity as compared to $26 \%$ of the global Internet user population [21].

In addition to social life, students use social media or Facebook for educational purposes. Through the Internet, they gather information and believe Facebook increases their knowledge (Ibid). Mingle et al conducted research entitled, 'Social media Usage and Academic Performance in Public and Private Senior High Schools'. As they observed, social media like Facebook have been seen as learning platforms to enhance students engagement and performance. They stated that "Social network sites (SNS) have become an interesting part of students' life as a result of their features and medium of usage."[18].

Despite the fact that Facebook or other social network sites help students to access different books and information to gain knowledge, it has its own impact on their academic performance or GPA (Grade Point Average) since they spend more time on social media instead of studying their lessons [21]. According to Knight-McCord (2016), in average college students spent eight hours a day on social media; this creates concerns on students' social life and academic duty. "College students have concern about their Internet usage balancing social life, extracurricular activities, and even past time jobs. In particular, $70 \%$ reported that they stay online longer than they intended." (2016:22). Students use this social media to relax themselves from assignment. However, "a balance between social media use and academic effort is imperative to improve students' grades" (Ibid).

\section{Results and Discussions}

In this section, an attempt was done to present both qualitative and quantitative data collected using questionnaires, focus group discussions and interviews. The primary data are substantiated using discourse analysis on some selected students profiles and secondary sources or other researches conducted in other areas for verification. The study is mainly focused on effects of facebook on university students socio-political making and unmaking. Hence, the section focuses on four sub-titles; face book usage and students academic performances, students face book use addictions (intensity of face book usage), face book use and students social capital and facebook use and students political activities/engagement.

The study also tried to consider different batches of students in the campus; $29 \%$ from first year 19\% from junior students (second year) and 52\% from sophomore students (from third year to six years).

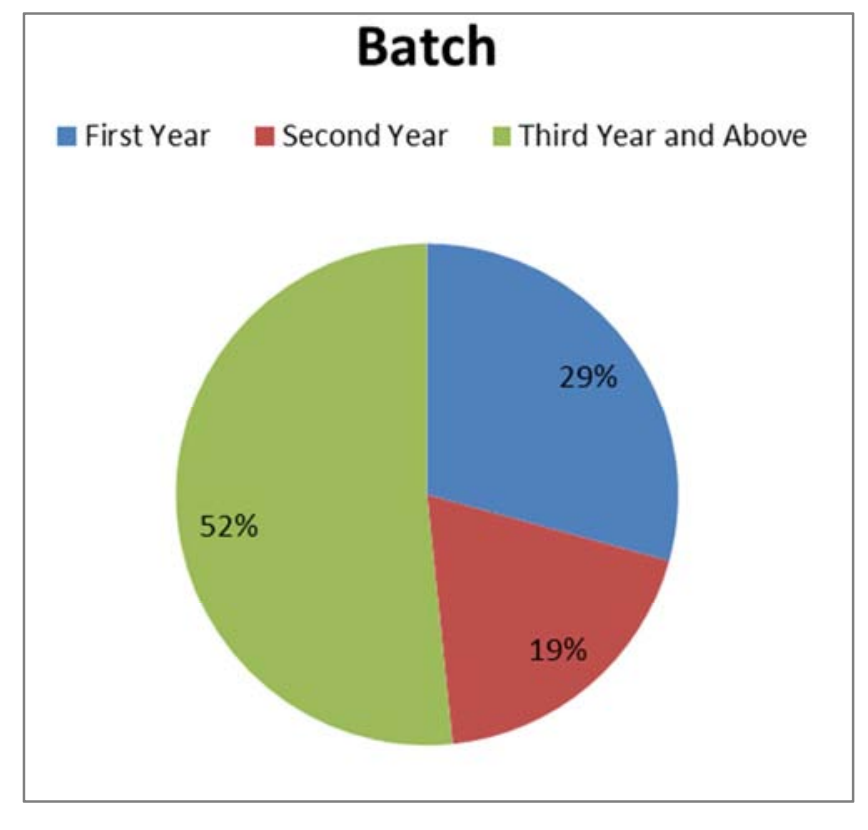

Figure 1. General Profiles and Information's.

As the above table shows 151, 122, 69 and 123 students answered that they access to facebook login one times a day, two times a day, three times a day and more than three times a day respectively. The finding sparsely exists. However, the existing truth is that absolute majority of the students $(67.5 \%)$ are access to face book login twice or more than two times a day.

Another issue concerning facebook usage is the time spent per login. As the above figure depicted from the data, $61.55 \%$ of the respondents confirmed as they are spending more than 30 minutes per each login on face book. Therefore, it is easy to conclude that students' in Ethiopian Universities on average spent more than 30 minutes per each login on face book. Participants of focus groups discussions and interviews also confirmed the finding of quantitative data. When we compare with the first data on how many times students' login facebook per day, absolute majority of the students were login face book two times and more within one day. Hence, it is possible to conclude those students in Ethiopian public Universities on average spent one hour and more times on facebook a day (Figure 2\&Figure 3 ). This is the highest time compare with other researches conducted in different higher institutions. 


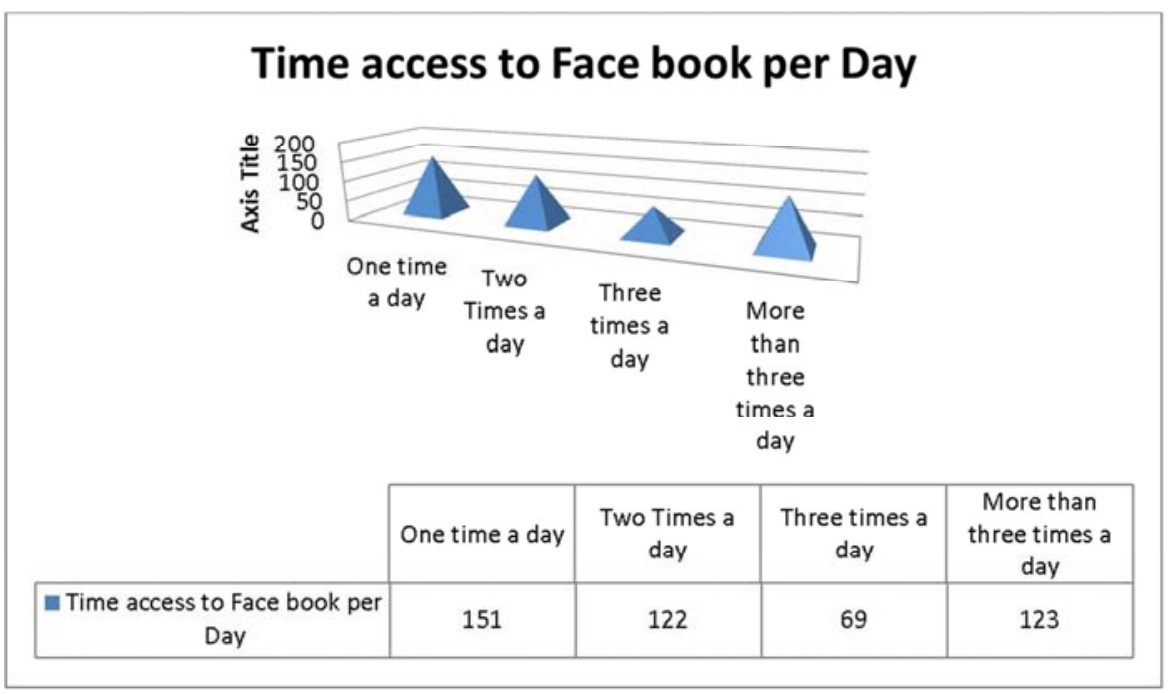

Figure 2. Time access to facebook per day.

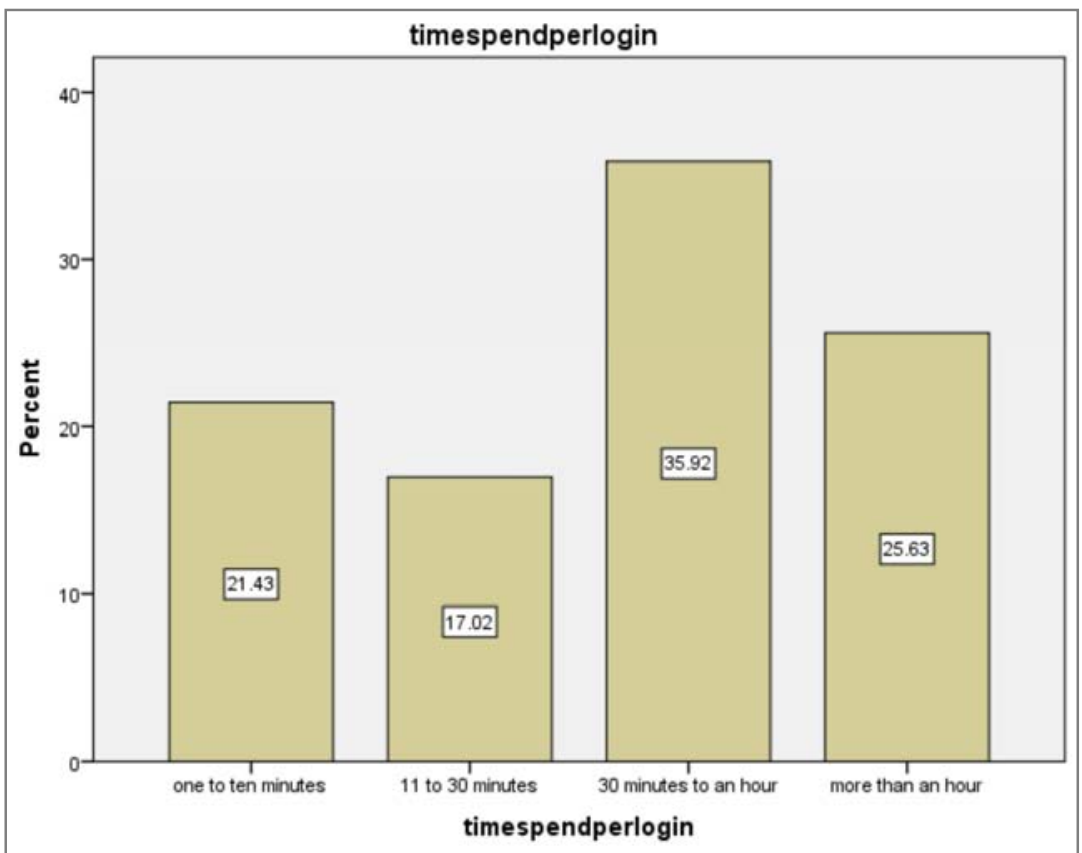

Figure 3. Time Spent on Facebook per login

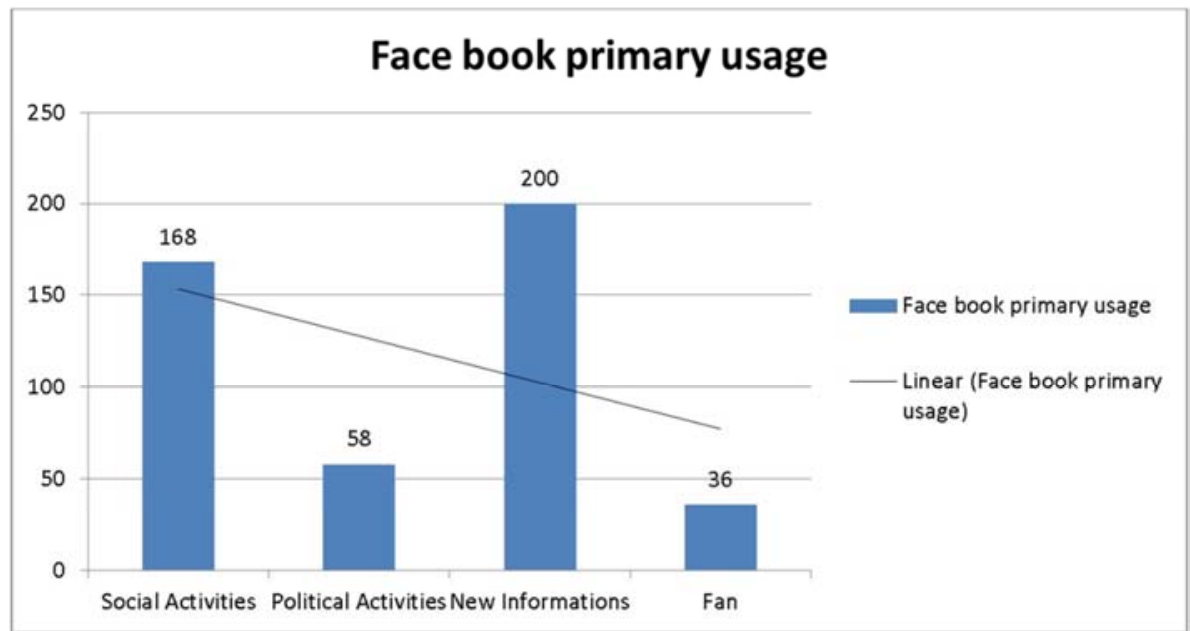

Figure 4. Facebook Primary Usage. 
As the above table depicted out of 477 students, 168 students answered that they use face book primarily for social activities, to chat with friends and parents. On the other hand, 200 students, which contain $41.5 \%$ the total sample population, said that they were login to facebook to get new information/check status updates of friends. Few students 58 and 36 students said that they were login to facebook primarily for political activities and fan respectively. According to this data, the primary use of facebook among Ethiopian university students in Ethiopia is primarily for access to new information followed by social engagement. However, as the researchers understand from participants of focus group discussions and interviews, seek of new information also includes political activities. On the other hand, Ethiopian university students were least interest to facebook fan and overt political activities as primary concern. Thus, it is possible to conclude that absolute majority of the university students $(76.72 \%)$ use facebook primarily to get new information and social activities (chatting with friends and parents).

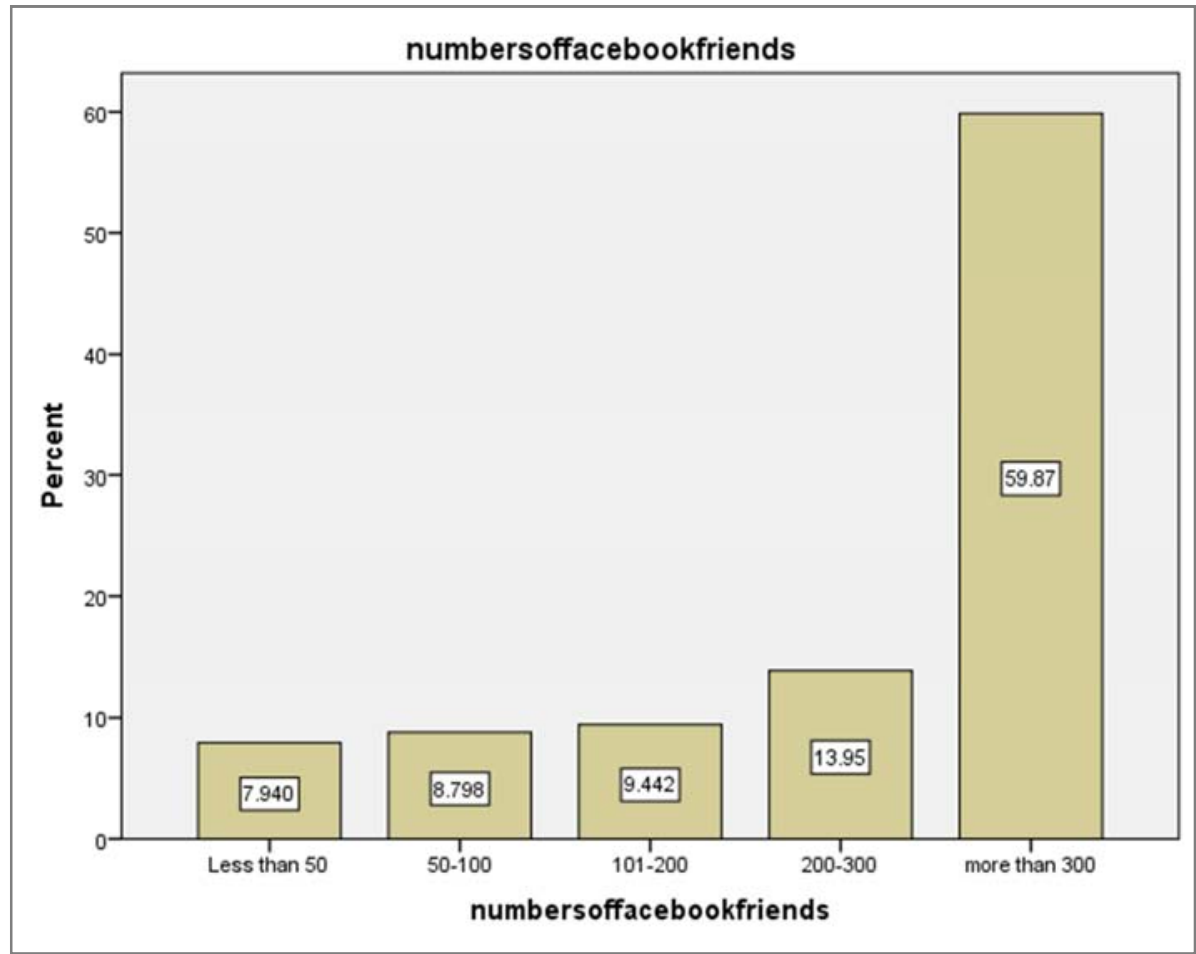

Figure 5. Numbers of Face-book Friends.

Concerning numbers of facebook friends' students answered that $7.94 \%, 8.78 \%, 13.95 \%$ and $59.87 \%$ answered that they have less than 50 , between 50 and 100, between 101 and 200, between 200 and 300 and more than 300 respectively. Hence, the data shows that majority of the students had more than 300 face book friends which shows that University students have much more friends on facebook.

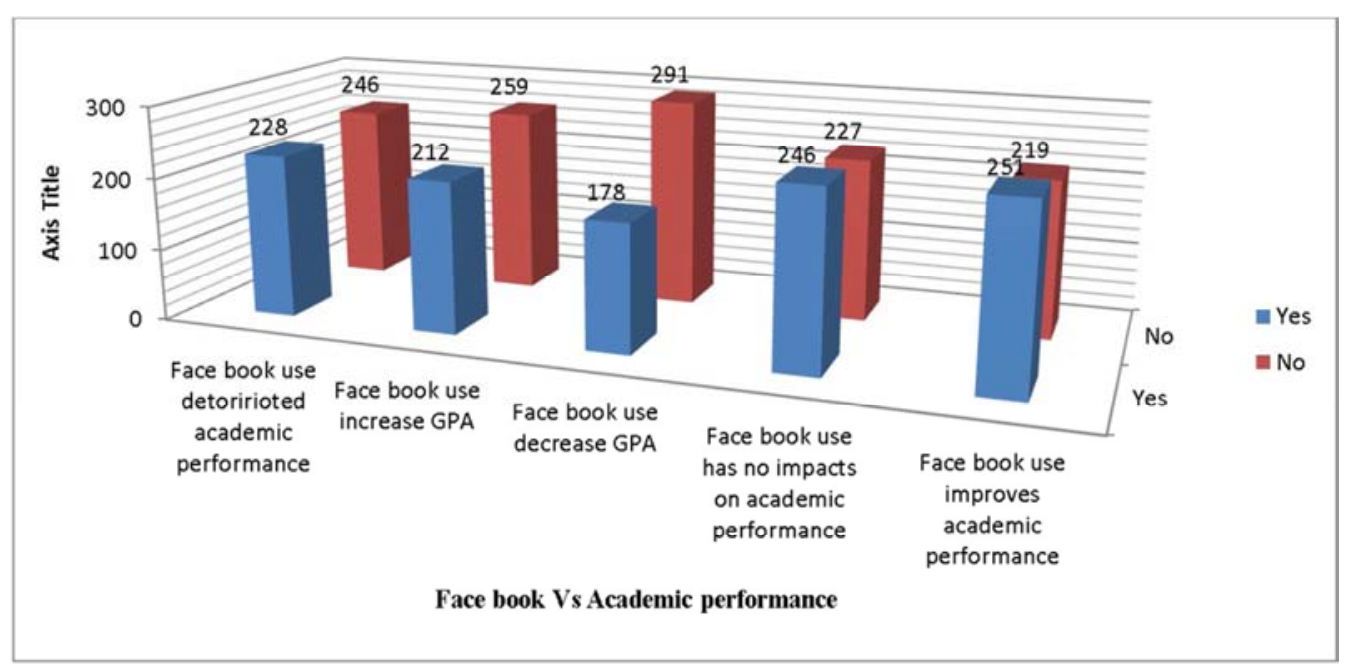

Figure 6. Face book usage Vs Academic performance. 
The effects of social media specially face book on university students academic performances reach its climax. Face book affects students study time, poor grammar and wrong spelling when socializing with social media, which mainly based on informal communication than the formal one (Nizam, 2016). On the other aspects, students who use face book appropriately can exploit its fruits through the way it contribute for the improvements of their academic performance. This section of the study focus on assessing the positive and negative effects of face book on students academic performances. For this purpose five objective questions is prepared and students were asked to answer yes or no for these questions. The answers was very mixed which shows that the effect is in perspectives meaning its positive and negative impacts on students' academic performance is determined based on individuals self assertiveness. For example if we see the responses one by one out of 472 students 228 students had the perception that face book usage deteriorated their academic performances while 246 students which is slightly more than the first groups answered that face book usage should not deteriorated their academic performance. In the same way, 212 students believed that facebook usage contribute for the incensement of their academic GPA while slight majority students (259) students perceived that face book usage did not have effects on their GPA.

Out of477 students 178 students answered that their GPA was decrease due to their intensive face book usage/after they started using face book while 291, majority students perceived that their GPA was not decreased after they started to use face book. In addition, 246 students believed that face book usage has no impacts on their academic performance while 227 students expressed their perception of face book usage has impacts on students academic performances. On the other expression, 251 students expressed their views that their academic performances improved after they started using face book while 219 students said that no improvement on their academic performances after they started using face book. The data from questionnaires resulted in complex answers, which is difficult to reach upon single conclusions and to verify these dilemmas the researchers held focus group discussions and the researchers understand that face book usage has both positive and negative impacts on users academic performances based on the nature of usage.

Students who use face book appropriately were benefited by getting new academic information by sharing from their friends on distances while some students were negligent of the importance of face book for academic purposes. This group, neither effected by face book addiction nor exploits the fruits of facebook for academic purposes. The third group of students is those who tend to addiction in using face book. This group's academic performance and GPA was deteriorated or decline after starting using face book. Therefore, it is possible to concluded that Ethiopian university students face book usage and academic performance is in perspective that some managed to exploit the positive side of face book for academic performance while others loss their academic performance due to intensive use of face book for non-academic purpose, according to focus group discussions long chat without significant reasons. Generally, the current status of Ethiopian University students (view from Amhara region) shows that majority of the students' academic performances and facebook usage has positive relations.

The other issues concerning youths face book usage is face book addiction. To measures the levels of face book usage intensity among university students, fourteen objective questions accompanied by discourse analysis and focus group discussions was presented here respectively. Students were asked to rate each questions as never, rarely, often and always having rectal scale from zero to four. According to Young (2011), if the average values of all questions rated below two the students are not addicted while if the average values is above two the students are addictive to face book usage. Students were asked whether they are staying on face book usage longer than the time they intended to stay and simple majority (166 students) confirmed as they stayed on face book use more than intended time rarely followed by (131 students) who answered often. Other students, 105 and 62 were answer never and always respectively. From this, it is possible to conclude that out of 464 students participating in the research 359 students confirmed as they are staying on face book use longer than the time the intended to use.

In addition, students are asked whether they prefer face book excitement over intimacy with parents and out of 456 respondents' 335 participants confirmed as they are preferring face book excitement over intimacy with parents. In similar way students were asked how often they were face complains from their colleges while staying on face book and out of 463 participants 336 participants confirmed as they were facing complains from their friends while using face book. Furthermore, participants were asked the questions how often do they login to face book before they have to do something else and few students answer never to do so while absolute majority confirm as they login to face book before something else they have to do. From the total participants (461), 381 participants or $82.6 \%$ of the participants confirmed, as they are engaging in face book login before accomplishing the work expected from them, majority of which confirmed as they do this rarely and often. Students are also asked as face book usage has impacts on their academic achievements and out of 466 participants, 292 confirmed as face book usage has impacts on their academic achievements either positively or negatively.

respondents asked the question 'how often do you defensive or secretive when any one ask them what they do on face book?' and out of 462 participants, 353 participants confirm that, as they are defensive or secretive when someone asks them what they are doing on face book. In similar way participants were asked how often they are anticipated when they go back to face book usage and from the total 462 participants, 370 participants confirmed as they 
were anticipated for face book use again after logout. Participants asked the question, 'do you fear that life without face book is difficult?' and simple majority of the participants believe that they do not fear life without face book is difficult followed by participants who rarely fear life without face book is difficult. The cumulative result shows that out of 458 participants, 258 (majority of the respondents) confirmed as they fear life without face book is difficult.

Respondents were asked the question 'how often do they block disturbing thoughts on face book?' and out of 460 total respondents, 362 respondents confirmed as they are blocking some disturbing thoughts on face book. On similar tone 125, 165, 109 and 62 participants responded never, rarely, often and always respectively on the questions 'how often do you irritate when someone bothers you while using face book. Out of the total 461 participants, 336 respondents confirmed as they are irritated when someone asked them what they are doing on face book.

As the above graph depicted out of the total respondents, 332 respondents face lose of sleep due to late night face book login. Participants asked question 'how often do they said just a few more minutes while using face book?' and from the total 414 research participants, 343 respondents confirmed as they are saying just a few minutes while using face book. For the question 'how often do you tried to cut down face book use and failed', 135 respondents responded as they never tried to do so while 136, 114 and 80 respondents answers rarely, often and always which qualified that majority of the respondents tried to cut down face book usage and failed to do so.

On the other hand, from 466 total respondents, 159 respondents responded, as they were never depressed with the absence of face book while 140, 102 and 65 respondents were answering rarely, often and always respectively. From this, it is possible to conclude, that majority of the respondents believe as they are depressed if face book is cutoff. From these total data the intensity/level of face book usage among university students in Ethiopia is calculated as follow;

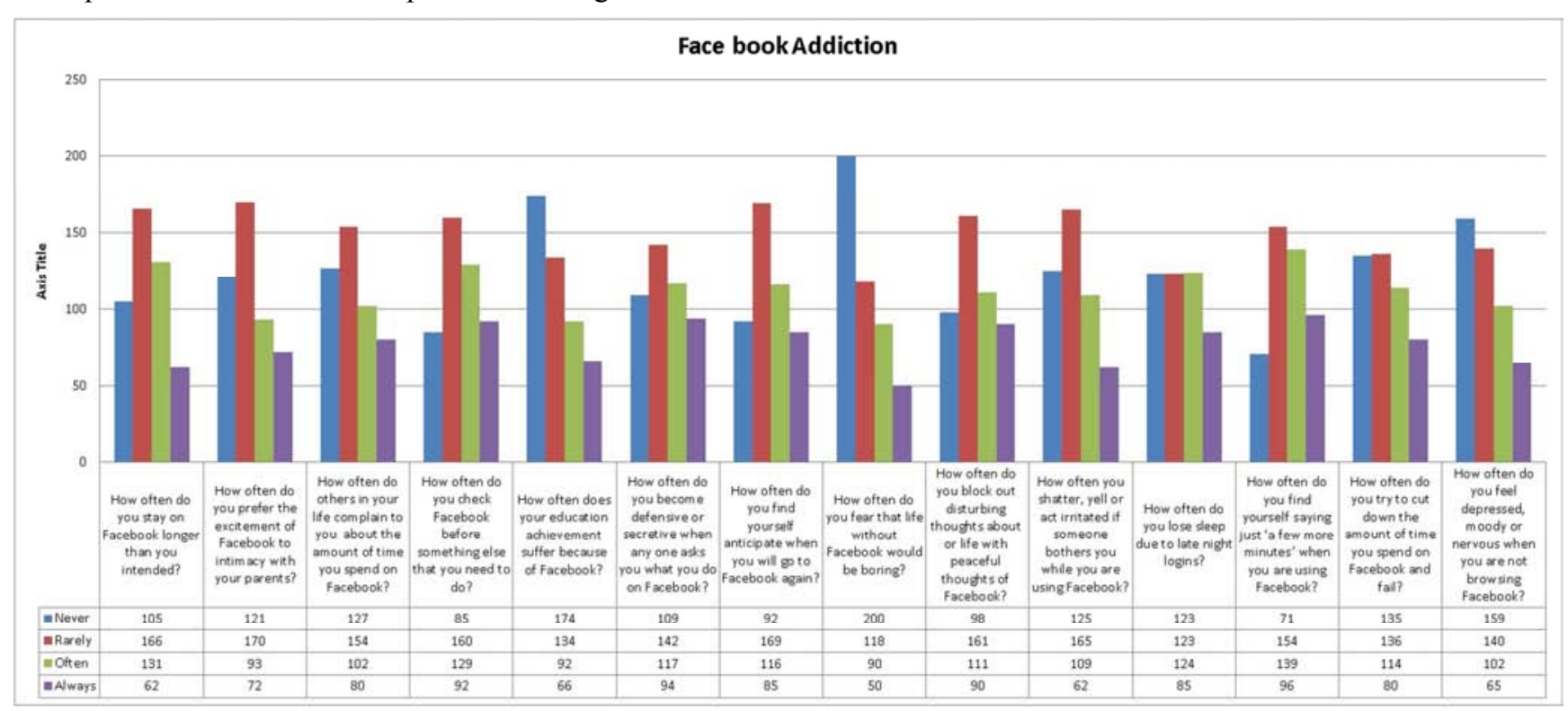

Figure 7. Intensity of Face book usage in Ethiopian University (Levels of Addictions).

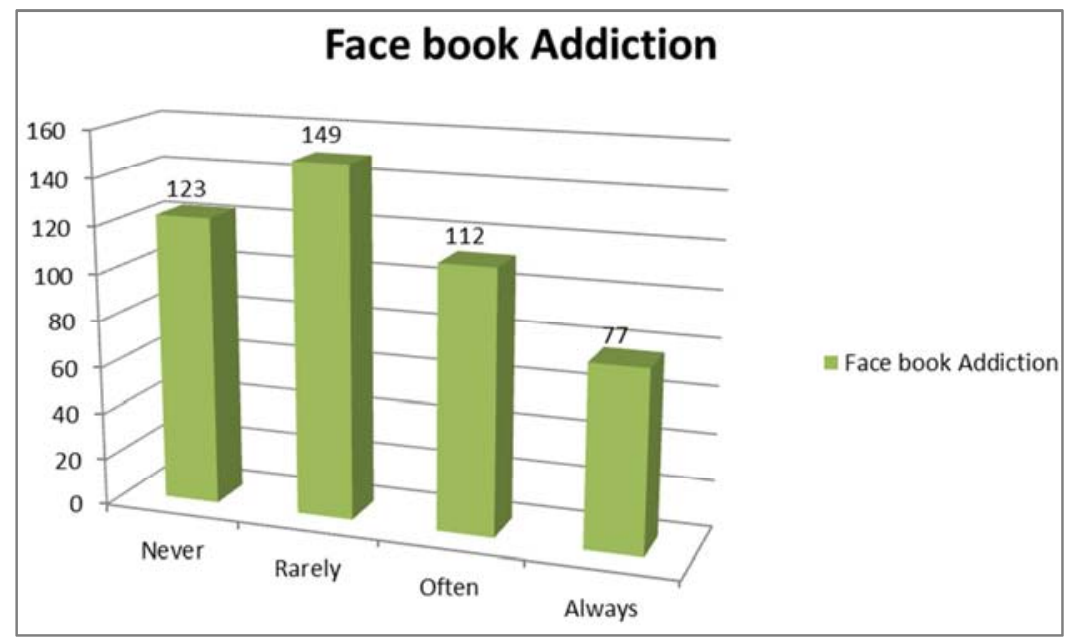

Figure 8. Facebook Addiction. 
As above graph depicted in average out of the total research participants, $73.3 \%$ were addictive to facebook usage at different stages. Therefore, majority of the students are addicted to facebook usage.

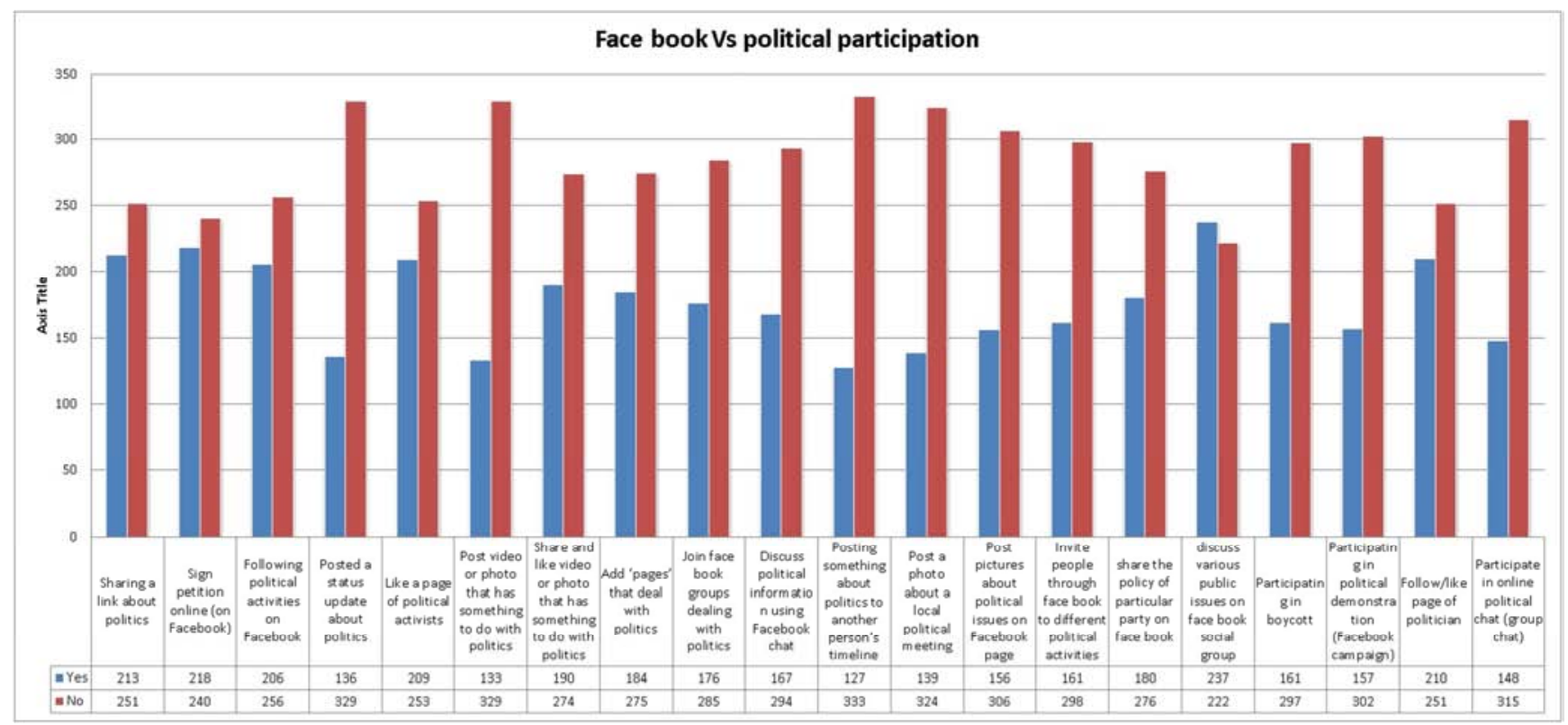

Figure 9. Facebook and Political participation.

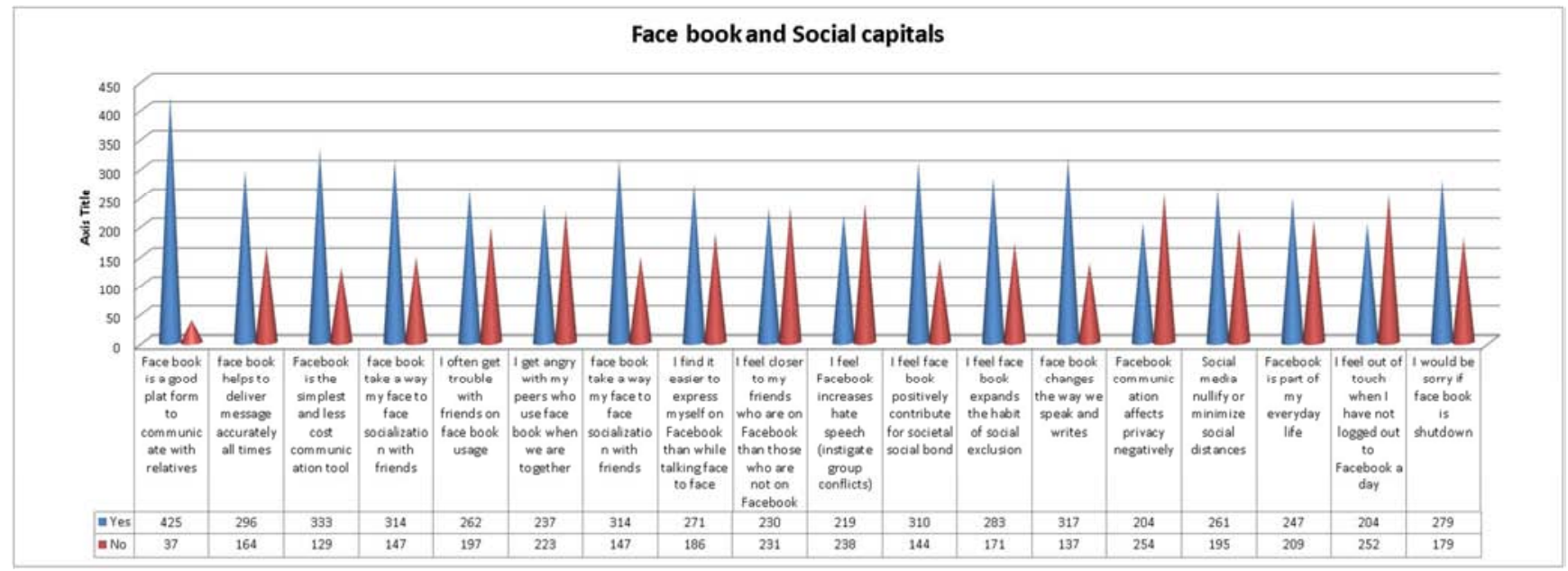

Figure 10. Face book usage and Students Social Capitals.

To assess university students' political engagement on face book twenty close-ended questionnaires accompanied with focus group discussions and interviews was presented hereunder in this sub-sections. Generally, the responses of target sample in all close-ended questionnaires, majority students responded as they were not actively participating in political activities. Out of the total respondents (460), 38.1\% responded as they engaged on facebook political activities while $61.9 \%$ confirmed, as they were not participated on facebook political activities. Therefore, it is possible to conclude that majority of the Ethiopian University students were passive on engagement on facebook overt political activities ${ }^{1}$.

1 This data is collected before the Ethiopian reform (premiership of Dr. Abiy Ahmed). Currently, overt political engagement and social media activism increase
The final concern of this study is to assess the effects of facebook usage on students interpersonal communication and social capitals. Many previous researches finding shows that facebook usage has both positive and negative effects on youth's interpersonal relations and social capitals specially university students. To assess the effects of facebook usage on Ethiopian university students social capitals, seventeen close ended questionnaires accompanied with focus group discussions and interviews were presented here. As the above graph depicted out of total respondents absolute majority of the students (92\%) have the perception that facebook is a good platform to communicate with friends and relatives. In similar talk $64 \%$ of the respondents responded that facebook help deliver message accurately at all time while $72 \%$ of the

in Ethiopia in which the University students are the major actors. 
respondents argued that facebook is the simplest and less cost communication tools.

On the other way $68 \%$ of the respondents express that facebook take away their face-to-face socialization with parents while $57 \%$ of the respondents express as they face trouble due to facebook login when they are playing together with friends. In support of this, participants of focus group discussion confirmed that facebook nullify social interaction especially social gathering, playing in-group and discussion because of all move to facebook while at social gathering. Overall the assessment on the effects of facebook on social capital, the finding shows both positive and negative effects. Facebook contribute positively for students social interaction with friends and relatives at distance area with less cost while facebook negatively affect social gathering.

\section{Concluding Remarks}

The general objective of this paper is to assess the effects of Face book on the making and unmaking of University students socio-political activities. To achieve the objective, both primary and secondary sources of data were collected and interpreted using both qualitative and quantitative methodologies of data analysis. As far as primary sources of data were concerned, first hand information was collected from target populations via questionnaires, interviews and Focus Group Discussions. Sixty-threeclose-ended questionnaires prepared and first hand information was collected from 500 University Students in Ethiopia. To substantiate and verify these quantitative data in-depth interviews was conducted with face book activists, students and social science professionals. As well as Focus Group Discussion was held with 160 students divided in to twenty groups in the sample universities. Furthermore, the primary data collected through multiple of methods and techniques were substantiated and verified by secondary sources. As far as secondary sources are concerned discourse analysis was done on some selected face book pages. In addition, researches conducted on facebook in different areas were used for comparing the results. After doing this, the researchers interpreted and analyzed the finding using the existing models and theories of social media. Using these data and conceptual framework the researchers reached upon the following conclusions;

The general assessment of facebook usage among Ethiopian University students in Ethiopia show that the highly engulfment of social media especially facebook bring both positive and negative effects on overall students' academic performance, social capital and political activities. The general usages of facebook show that Ethiopian universities students spent on average an hour and more time per a day. The finding shows that $73.3 \%$ of public University students are addictive to face book usage. Concerning the primary interests of facebook users, Ethiopian university students login to facebook primarily to get new information followed by social activities (chat with friends and parents). Concerning the effects of facebook usage on Ethiopian university students' academic performances, the finding is in perspective. Majority of the university students explain the positive contribution of facebook to students' academic performance while some other students were explained as facebook usage affects their academic performances negatively.

In similar manner, facebook usage has both positive and negative effects on Ethiopian University students interpersonal communication and social interactions. The finding shows that facebook helps students to deliver message accurately at all time, contact with relatives and friends at distance with less cost and easily while it deteriorated social gathering and discussion, individualism/loneness. However, in relation to facebook usage and political activism, the finding shows that majority of Ethiopian University students are passive in overtly participating in online political activism. Generally, it is possible to conclude that facebook has both positive and negative effects on Ethiopian university students sociopolitical activities, which seek attention to create awareness among university students in order to exploit the fruits of facebook absolutely and reduce the negative effects of facebook.

\section{Conflict of Interests}

The authors have not declared any conflicts of interests.

\section{References}

[1] Zephoria Digital Marketing (2016), Digital Marketing Trends for 2016.

[2] Facebook (2015), Facebook Reports fourth Quarter and full year 2015 Results, https://investor.fb.com/investornews/press...and...2015.../default.aspx.

[3] Firomsa Bedasa, (2014): Impacts of facebook usage on students academic performance, Munich, GRIN Vergal, http://www.grin.com/en/e-book/277559/impacts-of-facebookusage-on-students-academic-performance.

[4] Internet Society (2016), Global Internet Report 2016.

[5] Brando Hoover (2009): The First Amendment Implications of Facebook, Myspace, and Other Online Activity of Students in Public High Schools (Article).

[6] Kassahun G/Medhin (2014): The relationship of social networking to adolescent psychology adjustment in selected preparatory schools of Addis Ababa, MA Thesis, Addis Ababa.

[7] Internet world stats (2016): usage and population statistics, https://internetworldstats.com/

[8] Nebiat, N. and Girum, K. (2014): 'Relationship between Facebook practice and academic performance of University students, Asian Journal of Humanities and social science, V.2, Issue 2.

[9] Gagliardone, I. et al (2016): Mechachal: Online debates and elections in Ethiopia, From hate speech toengagement in social media, Creative Common. 
[10] Farrokhi, Farahman, (2012): Rethinking convenience sampling: defining quality criteria, theory and practice in language studies, Vol. 2, No. 4, pp 784-792.

[11] Alemayehu Shiferaw, (2010): Evaluating the Application of Human Rights Principles in Crime Investigation in Ethiopia (A case of Addis Ababa City Police), PhD Desirtation, University of South Africa.

[12] Bainbridge, J. et al (2011). MEDIA\& JOURNALISM. (2nd ed.), Oxford Univer. sity Press, Australia \&. New Zealand.

[13] Allen \&Unwin (2004). The Media, Politics and Public Life. Geoffrey craig, National Library of Australia.

[14] Tuggle, C. A., Huffman, S., \& Rosengard, D. (2007). A descriptive analysis of NBC's coverage of the 2004 Summer Olympics. Journal of Sports Media, 2(1), 53-75.

[15] Adesope, Y. R. and Ogan-Charles, G. (2015). Extent of social media usage by students for improved learning in Tertiary Institution. Journal of Mobile Computing \& Application, Vol. 2, Issue 2: Page 1-7.
[16] Bacearella. V. C, Timma. F, Wanger, Jan. H. Kietman, Ian, P.Mc Carthy (2018): Social media? It's serious! Understanding the dark side of social media, European Management Journal, Vol. 36, Pp 431-438.

[17] McCord, J. (2016). What social media sites do college students use most? Journal of Undergraduate Ethnic Minority Psychology - 2016 Spring; 2: Page 21-26.

[18] Mingle et al (2016). A Comparative Analysis of Social Media Usage and Academic Performance in Public and Private Senior High Schools. Journal of Education and Practice, Vol.7, No.7: Page 13-22.

[19] Caer, R. et al (2013). Facebook: A literature review. New media \& society, Sage, Page 983-1002.

[20] Perrin, A. (2015). Social Media Usage: 2005-201565\% of adults now use social networking sites - a nearly tenfold jump in the past decade. Pew Research Center: Page 1-11.

[21] Noonan, C and Piatt, A. (2014). Global Social Media Directory: A Resource Guide. Pacific Northwest National Laboratory Richland, Washington99352. 